Research Paper

\title{
Synthesis and in vitro experiments of carcinoma vascular endothelial targeting polymeric nano-micelles combining small particle size and supermagnetic sensitivity
}

\author{
Yi Zhang ${ }^{1 *}$, Jielin Pan $^{1 *}$, Qilan $\mathrm{Xu}^{1^{*}}$, Hao Li³ ${ }^{3}$ Jianhao Wang${ }^{2}$, Chao Zhang ${ }^{2 \bowtie}$, Guobin Hong ${ }^{1 凶}$ \\ 1. Department of Radiology, Fifth Affiliated Hospital, Sun Yat-Sen University, Zhuhai 519000, P. R. China \\ 2. Guangdong Provincial Key Laboratory of Sensor Technology and Biomedical Instruments (Sun Yat-sen University), School of Biomedical Engineering, Sun \\ Yat-Sen University, Guangzhou 510006, P. R. China \\ 3. Institute of Electronic Paper Display, South China Academy of Advanced Optoelectronics, South China Normal University, Guangzhou 510006, P. R. China
}

*These authors contributed equally to this work.

$\triangle$ Corresponding authors: Guobin Hong, Department of Radiology, Fifth Affiliated Hospital, Sun Yat-Sen University, Zhuhai 519000, P. R. China. Tel.: +86-756-2528666; E-mail: honggb@mail.sysu.edu.cn and Chao Zhang, Guangdong Provincial Key Laboratory of Sensor Technology and Biomedical Instruments (Sun Yat-sen University), School of Biomedical Engineering, Sun Yat-Sen University, Guangzhou 510006, P. R. China. Tel.: +86-20-39332145; Fax: +86-20-39332312; E-mail: zhchao9@mail.sysu.edu.cn

(c) Ivyspring International Publisher. This is an open access article distributed under the terms of the Creative Commons Attribution (CC BY-NC) license (https://creativecommons.org/licenses/by-nc/4.0/). See http://ivyspring.com/terms for full terms and conditions.

Received: 2017.10.03; Accepted: 2018.02.04; Published: 2018.03.08

\begin{abstract}
Objective: To construct carcinoma vascular endothelial-targeted polymeric nanomicelles with high magnetic resonance imaging (MRI) sensitivity and to evaluate their biological safety and in vitro tumor-targeting effect, and to monitor their feasibility using clinical MRI scanner.

Method: Amphiphilic block copolymer, poly(ethylene glycol)-b-poly( $\varepsilon$-caprolactone) (PEG-PCL) was synthesized via the ring-opening polymerization of $\varepsilon$-caprolactone $(C L)$ initiated by poly (ethylene glycol) (PEG), in which cyclic pentapeptide Arg-Gly-Asp (cRGD) was conjugated with the terminal of hydrophilic PEG block. During the self-assembly of PEG-PCL micelles, superparamagnetic $\mathrm{Y}-\mathrm{Fe}_{2} \mathrm{O}_{3}$ nanoparticles $(11 \mathrm{~nm})$ was loaded into the hydrophobic core. The cRGD-terminated $\mathrm{y}-\mathrm{Fe}_{2} \mathrm{O}_{3}$-loaded polymeric micelles targeting to carcinoma vascular endothelial cells, were characterized in particle size, morphology, loading efficiency and so on, especially high MRI sensitivity in vitro. Normal hepatic vascular endothelial cells (ED25) were incubated with the resulting micelles for assessing their safety. Human hepatic carcinoma vascular endothelial cells (T3A) were cultured with the resulting micelles to assess the micelle uptake using Prussian blue staining and the cell signal intensity using MRI.

Results: All the polymeric micelles exhibited ultra-small particle sizes with approximately $50 \mathrm{~nm}$, high relaxation rate, and low toxicity even at high iron concentrations. More blue-stained iron particles were present in the targeting group than the non-targeting and competitive inhibition groups. In vitro $\mathrm{MRI}$ showed $\mathrm{T}_{2} \mathrm{WI}$ and $\mathrm{T}_{2}$ relaxation times were significantly lower in the targeting group than in the other two groups.

Conclusion: $\mathrm{Y}-\mathrm{Fe}_{2} \mathrm{O}_{3}$-loaded PEG-PCL micelles not only possess ultra-small size and high superparamagnetic sensitivity, also can be actively targeted to carcinoma vascular endothelial cells by tumor-targeted cRGD. It appears to be a promising contrast agent for tumor-targeted imaging.
\end{abstract}

Key words: micelles, PEG-PCL, cRGD, $\gamma-\mathrm{Fe}_{2} \mathrm{O}_{3}, \mathrm{MRI}$

\section{Background}

Cancer is a leading cause of death worldwide, resulting in 8.8 million deaths in 2015 and accounting for $17 \%$ of all deaths. The World Health Organization estimates that malignant tumor deaths will continue to increase and exceed 13.1 million in the year 2030 [1]. 
Angiogenesis is required for tumor growth and invasion [2-4]. The integrin av $\beta 3$ receptor is highly expressed on the cell surface of a variety of malignant tumors and tumor angiogenesis endothelial cells, whereas it has low or undetectable expression in the resting or mature endothelial cells [5-6]. Recent research on early diagnosis and tumor therapy has focused on early diagnosis, early residual micro-lesion detection, anti-angiogenic therapy and non-invasive monitoring using specific molecular targets (such as $a v \beta 3$ and $a v \beta 5$ ), which are upregulated by tumor angiogenesis.

Application of effective contrast agents has been regarded as a feasible means to improve lesion detection rates and qualitative diagnostic capabilities. However, the commonly-used clinical contrast agents, such as gadolinium diethylenetriamine pentaacetic acid (Gd-DTPA) and superparamagnetic iron oxide nanoparticles (SPION), have low sensitivity, a short half-life, and non-specific distribution, and they are difficult to modify, which is not conducive to early tumor diagnosis and the detection of micro-lesions [7-13]. Magnetic resonance (MR) molecular imaging that is supported by nanotechnology development is an emerging technique for early tumor diagnosis. Nanotechnology has the advantage of small size, long half-life in blood, and better passive and active tumor targeting. Polymeric micelles are suitable contrast agent carriers and are excellent for targeted delivery of hydrophobic drugs [7,14,15].

In this study, we synthetised a poly(ethylene glycol)- $b$-poly( $\varepsilon$-caprolactone) (PEG-PCL) micelles surface-modified with integrin av $\beta 3$ receptor, cyclic pentapeptide Arg-Gly-Asp (cRGD), and encapsulated with superparamagnetic $\gamma-\mathrm{Fe}_{2} \mathrm{O}_{3}$ nanoparticles for tumor-targeted magnetic resonance imaging (MRI). The purpose of this study was to explore a multifunctional polymeric micellar carrier with high carcinoma vascular endothelial cells- uptake and targeting effect, and magnetic sensitivity as an effective MRI contrast agents.

\section{Materials and methods}

\section{Reagents and equipment}

$\varepsilon$-Caprolactone $(99 \%)$ was purchased from Shenzhen Esun Industrial Co., Ltd., China. Monomethoxy-terminated (mPEG; molecular weight: $2,000 \mathrm{~g} / \mathrm{mol}$ ) and monocarboxy-terminated polyethylene glycol (COOH-PEG; molecular weight: 2,000 g/mol) were purchased from Sigma-Aldrich and Beijing Jiankai Co., Ltd., China, respectively. Cyclic pentapeptide Arg-Gly-Asp (cRGD, 95\%) was purchased from Chinapeptides Co., Ltd., China. Iron pentacarbonyl $\left(\mathrm{Fe}(\mathrm{CO})_{5}, \geq 98 \%\right)$ was from Beijing Xin
Ding Pengfei Technology Development Co., Ltd., China, and human normal hepatic vascular endothelial cells (ED25) were obtained from the Experimental Animal Center of Sun Yat-sen University. T3A, a human hepatic carcinoma vascular endothelial cell, was obtained from the Beijing Beina Chuanglian biological technology research institute.

${ }^{1} \mathrm{H}$ NMR spectra and matrix-assisted laser desorption/ionization (MALDI) time-of-flight (TOF) spectrometry (Ultraflex TOF/TOF III, Bruker, Germany) were used for determining the chemical structure of resulting polymers. An ultrasonic processor (Sonicator S-4000, Sonicator, USA) was used for the preparation of the micelles. Transmission electron microscopy (JEOL JEM - 1400, JEOL Ltd., Japan), and Zeta Potential \& Particle-Size Analyzer (Zetasizer Nano ZS90, Malvern instruments Ltd., UK) were used to characterize the micelle's morphology and particle size. A UV/Vis spectrophotometer (Beckman DU 730, CA, USA) was used to determine the loading efficiency of $\gamma-\mathrm{Fe}_{2} \mathrm{O}_{3}$ nanoparticles of resulting micelles. an inverted fluorescence microscope (Olympus IX71, Olympus, Germany), a polarizing microscope (DM2500p, Leica, Germany) and a multifunctional microplate reader (BioTek Synergy4, BioTek Instruments Inc., USA) were involved for cell biology experiments. In vitro MRI experiments were performed using a clinical 1.5-T system (Philips NT Intera CV, Philips Medical Systems).

\section{Synthesis and characterization of $\mathrm{Y}-\mathrm{Fe}_{2} \mathrm{O}_{3}$ nanoparticle}

In the atmosphere of argon, $4.5 \mathrm{~mL}$ of dioctyl ether, $165 \mu \mathrm{L}$ of oleic acid, $495 \mu \mathrm{L}$ of oleylamine and 90 $\mu \mathrm{L}$ of $\mathrm{Fe}(\mathrm{CO})_{5}$ were mixed by magnetic stirring and heated to $280^{\circ} \mathrm{C}$. After cooling for 1 hour to room temperature, $200 \mu \mathrm{L}$ of the mixture was precipitated in $1.5 \mathrm{~mL}$ of ethanol and then centrifuged for 5 minutes to remove the supernatant. Subsequently, every aliquot of the resulting precipitate dissolved in $0.75 \mathrm{~mL}$ of $\mathrm{n}$-hexane was mixed with $0.75 \mathrm{~mL}$ of ethanol for further precipitation at least twice. Finally, the crude product was dissolved in $1 \mathrm{~mL}$ of $\mathrm{n}$-hexane with the addition of $5 \mu \mathrm{L}$ of oleic acid [16].

A small amount of product was air-dried with the nitrogen and sufficiently dispersed in the sodium dodecyl sulfate (SDS) aqueous solution $(5 \% \mathrm{w} / \mathrm{w})$ under ultrasound action. A drop of the sample solution was added to the surface of a carbon-covered copper mesh (400 mesh) till dried out. The morphology of the resulting nanoparticles was observed using a transmission electron microscope $(120 \mathrm{kV}, \times 50,000$ magnification). 


\section{Synthesis of methoxy- and carboxy-termi- nated amphiphilic biblock copolymer (mPEG-PCL and COOH-PEG-PCL)}

After $2.0 \mathrm{~g}$ of mPEG was dried thoroughly for 2 hours at $60^{\circ} \mathrm{C}$ in vacuum, a small amount of stannous octoate was added in a dropwise manner. The mixture kept drying for 30 minutes. Since cooling to room temperature, $4.0 \mathrm{~g}$ of $\varepsilon$-caprolactone and 10-15 $\mathrm{ml}$ of toluene were added and stirred at $120^{\circ} \mathrm{C}$ for 12 hours. The final product was obtained by in-ether precipitation. Similar methods were performed for synthesizing carboxyl-terminated poly(ethylene glycol)- $b$-poly( $\varepsilon$-caprolactone) (COOH-PEG-PCL). A small quantity of product was dissolved in deuterated chloroform $\left(\mathrm{CDCl}_{3}\right)$ for ${ }^{1} \mathrm{H} \mathrm{NMR}$ determination.

\section{Synthesis of cRGD-terminated PEG-PCL block copolymers (cRGD-PEG-PCL)}

$1.0 \mathrm{~g}$ of COOH-PEG-PCL, $0.017 \mathrm{~g}$ of 1-ethyl-3-(3-dimethylaminopropyl)-carbodiimide (EDC) and $0.013 \mathrm{~g}$ of N-hydroxysuccinimide (NHS) were codissolved in chloroform and stirred for 2-3 hours at $35^{\circ} \mathrm{C}$ in the atmosphere of argon. Subsequently, $0.06 \mathrm{~g}$ of cRGD was added and keep constant for 12 hours. The concentrated solution was added dropwise to ultrapure water under sonication to construct polymeric micelles by self-assembly. After the removal of excess chloroform by rotary evaporation, the resulting micelle solution were dialyzed using dialysis tube (cut-off molecular weight: $14 \mathrm{k} \mathrm{Da}$ ) for 3 days. The final product was obtained by lyophilization of the dialysate. A small quantity of sample was dissolved in acetonitrile and characterized using matrix-assisted laser desorption/ ionization (MALDI) time-of-flight (TOF) spectrometry, with a-cyano-4- hydroxycinnamic acid as a reference matrix.

\section{Preparation of $\mathrm{Y}-\mathrm{Fe}_{2} \mathrm{O}_{3}$-loaded PEG-PCL micelles}

As the tumor-targeting ligand cRGD molar concentration is determined with $0 \%, 25 \%$ and $100 \%$, the corresponding cRGD-PEG-PCL mass with $0 \mathrm{mg}$, $4.125 \mathrm{mg}$ and $16.5 \mathrm{mg}$, and the mPEG-PCL mass with $15 \mathrm{mg}, 11.25 \mathrm{mg}$ and $0 \mathrm{mg}$ respectivel, was dissolved in $1.5 \mathrm{~mL}$ of dichloromethane overnight. Hereinto, all the mole number of copolymer $\left(2.5 \times 10^{-6} \mathrm{~mol}\right)$ are same as mentioned above. At the same time, the appropriate amount of hexane solution containing $\gamma-\mathrm{Fe}_{2} \mathrm{O}_{3}$ was drying under argon till weighting up to 2 $\mathrm{mg}$, and then dissolved in $1.5 \mathrm{~mL}$ of dichloromethane. The two solutions were mixed and then slowly dropped into $15 \mathrm{~mL}$ of ultrapure water under sonication. After the removal of remaining dichloromethane, the resulting solution was centrifuged at low speed for 3 minutes to discard the non-encapsulated $\gamma-\mathrm{Fe}_{2} \mathrm{O}_{3}$ nanoparticles at the bottom of centrifuge tube.

\section{Characterization of $\mathrm{Y}-\mathrm{Fe}_{2} \mathrm{O}_{3}$-loaded PEG-PCL micelles}

A droplet of micelle solution was added on the surface of a carbon-covered copper mesh (400 mesh), dried overnight at room temperature, and stained with a droplet of $0.02 \%(\mathrm{w} / \mathrm{w})$ phosphotungstic acid aqueous solution (PTA) for 30 seconds. Till dried out, some micelles were observed using a transmission electron microscope $(120 \mathrm{kV}, \times 50,000$ magnification). In addition, the average micelle diameter was measured using Zeta Potential \& Particle-Size Analyzer at $25^{\circ} \mathrm{C}$ after 10 -times dilution.

The loading efficiency and encapsulation efficiency of $\gamma-\mathrm{Fe}_{2} \mathrm{O}_{3}$ in micelles was analyzed using phenanthroline - iron (II) UV-visible spectrophotometry [17]. Briefly, $1 \mathrm{~mL}$ of micelle solution, $0.5 \mathrm{~mL}$ of $10 \%$ hydroxylamine hydrochloride solution, $1 \mathrm{~mL}$ of $0.15 \%$ phenanthroline solution and $2.5 \mathrm{~mL}$ of $1 \mathrm{~mol} / \mathrm{L}$ sodium acetate solution were added to the flask and diluted with ultrapure to $25 \mathrm{~mL}$. The corresponding $\mathrm{\gamma}-\mathrm{Fe}_{2} \mathrm{O}_{3}$ content was calculated according to the absorbance value at $508 \mathrm{~nm}$.

\section{Cytotoxicity}

Human hepatic vascular endothelial cells (ED25) were seeded in 96-well plates $(5,000$ cells/well) for 24 hours prior to application of increasing iron concentrations in the micelle solutions $(2.5,5,10,20$ and $40 \mu \mathrm{g} / \mathrm{mL})$. After another 24-hour incubation period, the polymer solutions were replaced with $180 \mu \mathrm{L}$ medium and $20 \mu \mathrm{L}$ (3-(4,5-dimethylthiazol-2-yl)-2,5-diphenyltetrazolium bromide) (MTT). Cells were incubated for another 4 hours at $37^{\circ} \mathrm{C}$ before the un-reacted dye was removed and $200 \mu \mathrm{L}$ dimethylsulfoxide (DMSO) was added. A value of absorbance was quantified using an enzyme-labeled instrument at wavelengths of $570 \mathrm{~nm}$. $\gamma-\mathrm{Fe}_{2} \mathrm{O}_{3}$ nanoparticles were fully dispersed in $2 \%$ Tween 80 solutions to make aqueous solutions containing the same iron concentration. The cell survival rate was calculated as follows: (experimental group A value/Control group A value) $\times 100 \%$.

\section{Prussian blue staining}

The human hepatic carcinoma vascular endothelial cell line (T3A) was cultured on 24-well plates $\left(2.5 \times 10^{4} /\right.$ well $)$ in RPMI-1640 medium supplemented with $10 \%$ fetal bovine serum and $1 \%$ antibiotic $(100 \mathrm{U} / \mathrm{L}$ penicillin and $100 \mu \mathrm{g} / \mathrm{mL}$ streptomycin) together with 3 groups of micelle solutions $(250 \mu \mathrm{L})$ at iron concentrations of $40 \mu \mathrm{g} / \mathrm{mL}$ (for the non-target group, target group and 
competition suppression group, the cRGD density is $0 \%, 25 \%$ and $100 \%$, respectively) for 2 hours. Cells were washed three times with phosphate-buffered saline (PBS), fixed with $4 \%$ glutaraldehyde for $10 \mathrm{~min}$, and further washed with PBS for twice. Cells were incubated at $37^{\circ} \mathrm{C}$ with $150 \mu \mathrm{L}$ Prussian blue solution (comprising an equal volume of $2 \%$ hydrochloric acid aqueous solution and $2 \%$ potassium ferrocyanide (II) trihydrate) for $30 \mathrm{~min}$. After washing with PBS for twice, iron staining was observed using a polarizing microscope.

\section{In vitro MR Imaging}

\section{Polymeric micelle MR Imaging}

The initial iron concentration in the 3 micelle groups was diluted to $1.6 \mathrm{mg} / \mathrm{mL}$ with water, and 5 concentration gradients were constructed (original concentration, $1 / 2,1 / 4,1 / 8$ and $1 / 16$ of original concentration).

The signal intensity and relaxation times of the 3 micelle groups at different iron concentrations were measured using a 1.5 T MRI scanner (Philips Intera). The imaging sequence included T1-weighted images (T1WI) (repetition time, TR, $300 \mathrm{~ms}$; echo time, TE, 7 ms), fast spin echo (FSE) T2WI (TR 3000 ms, TE 105 $\mathrm{ms}), \mathrm{T} 1$ - mapping, and T2-mapping.

T1 relaxation data were acquired using a single-section multi-spin-echo sequence mixed inversion recovery spin-echo sequence with an inversion recovery pulse with the following parameters: TR (spin-echo pulse), $3500 \mathrm{~ms}$; TR (inversion recovery pulse), $4000 \mathrm{~ms}$; inversion time $400 \mathrm{~ms}$; TE, 20-160 ms for eight steps; matrix, 256 $\times 256$; section thickness, $2 \mathrm{~mm}$; and field of view (FOV), 180 $\mathrm{mm} \times 108 \mathrm{~mm}$. A $30 \mathrm{~mm}^{2}$ circular region of interest (ROI) area was selected in each sample and the T1 relaxation time was determined.

T2 relaxation time was measured using a multi-spin-echo sequence with the following parameters: TR $2000 \mathrm{~ms}$; TE, 20-160 msec for eight steps; and FOV, $180 \mathrm{~mm} \times 108 \mathrm{~mm}$. A $30 \mathrm{~mm}^{2}$ circular $\mathrm{ROI}$ area was selected and the value of $\mathrm{T} 2$ relaxation time was obtained.

\section{Cell MR Imaging}

T3A cells, at a density of $1 \times 10^{5}$ cells, were cultured in 24-well plates in RPMI-1640 medium supplemented with $5 \%$ fetal bovine serum and $1 \%$ antibiotics (100 U/L penicillin and $100 \mu \mathrm{g} / \mathrm{mL}$ streptomycin) overnight. Then the medium was discarded and cells were washed once with PBS, and incubated in $300 \mu \mathrm{mol} / \mathrm{L}$ cobalt chloride $\left(\mathrm{CoCl}_{2}\right)$ for 24 hours. Then the medium was discarded, washed with PBS 3 times and incubated in $250 \mu \mathrm{L}$ micellar solution at an iron concentration of $0.5 \mu \mathrm{g} / \mathrm{mL}$ for 2 hours.
Cells were washed twice with PBS solution, $0.25 \%$ trypsin was added, and the digestion stopped with 1 $\mathrm{mL}$ medium. Then the cells were suspended in $1 \mathrm{~mL}$ $2 \%$ agarose solution after centrifugation, cooling, solidification at room temperature, stored at $4^{\circ} \mathrm{C}$ prior to scanning.

Cells were scanned using a $1.5 \mathrm{~T}$ MRI scanner (Philips Intera) to measure the signal intensity and T2 relaxation time. The imaging sequence includes T1WI (TR, 300 ms; TE, 7 ms), FSE T2WI (TR 3000 ms; TE 105 $\mathrm{ms})$. T2 relaxation time was measured by multi-spin-echo sequence using the following parameters: TR $2000 \mathrm{~ms}$; TE, 20-160 $\mathrm{msec}$ for eight steps; and FOV, $180 \mathrm{~mm} \times 108 \mathrm{~mm}$. A $30 \mathrm{~mm}^{2}$ circular area of ROI was selected and the value of $\mathrm{T} 2$ relaxation time was obtained.

\section{Statistical analysis}

All results are expressed as the mean \pm standard deviation. A paired $t$-test for all statistical analysis between two groups was performed using SPSS 16.0 software (SPSS Inc, Chicago, IL, USA). $P$ values less than 0.05 were considered to be statistically significant.

\section{Results}

\section{Synthesis and characterization of polymeric micelles}

The synthesized $\gamma-\mathrm{Fe}_{2} \mathrm{O}_{3}$ nanoparticles have a uniform particle size of $11 \mathrm{~nm}$ (Figure 1). In the ${ }^{1} \mathrm{H}$ NMR spectra, block copolymers had signals at 3.65 and $4.07 \mathrm{ppm}$, corresponding to characteristic methylene proton peaks of mPEG and PCL, respectively, in the repeat units. The PCL molecular weight, calculated by integration of the peak area, was about $3900 \mathrm{~g} / \mathrm{mol}$. These results suggested that mPEG successfully initiated PCL ring-opening polymerization to form the amphiphilic block copolymer mPEG-PCL. The ${ }^{1} \mathrm{H}$ NMR spectra of block copolymers COOH-PEG-PCL showed that the PCL hydrophilic and hydrophobic ratio and molecular weight were similar to that of mPEG-PCL. A notable peak was detected at $\mathrm{m} / \mathrm{z} 604.245$ in the MALDI-TOF mass spectrum after cRGD encapsulation, which was consistent with the molecular weight of cRGD, indicating that cRGD was successfully linked with the block polymer.

The average particle size was measured using a laser nano-granulometer. The average particle diameter of non-targeting $\gamma$ - $\mathrm{Fe}_{2} \mathrm{O}_{3}$-loaded mPEG-PCL micelles was $38.59 \pm 9.82 \mathrm{~nm}$ (Fig. 2a) and that of tumor-targeting $\gamma$ - $\mathrm{Fe}_{2} \mathrm{O}_{3}$-loaded cRGD-PEG-PCL micelles was $44.78 \pm 14.95 \mathrm{~nm}$ (Fig. 2b), both of which are close to $50 \mathrm{~nm}$. 


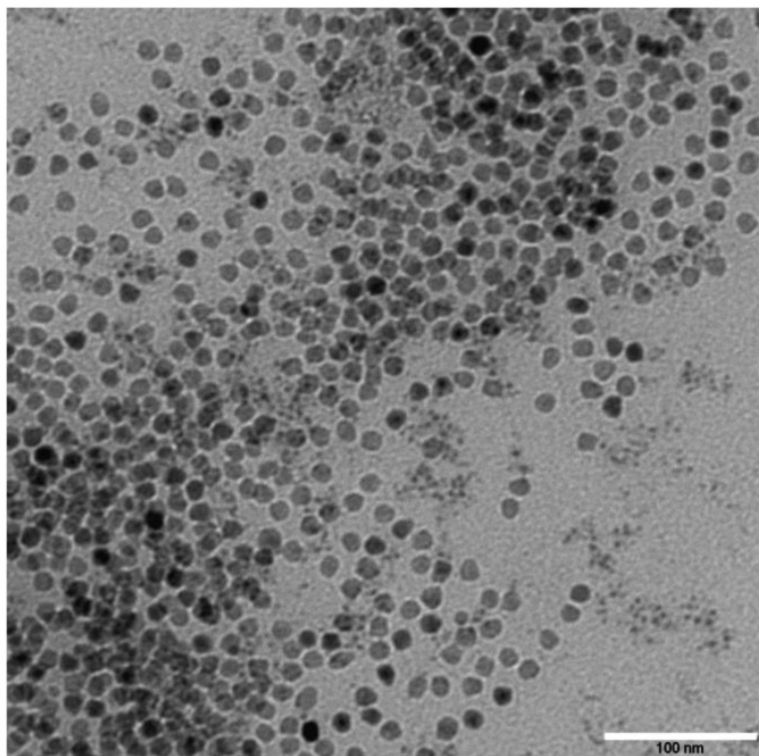

Figure 1. TEM photos of $\mathrm{Y}-\mathrm{Fe}_{2} \mathrm{O}_{3}$ nano-particle. The synthesized $\mathrm{y}-\mathrm{Fe}_{2} \mathrm{O}_{3}$ nanoparticles have a uniform particle size.
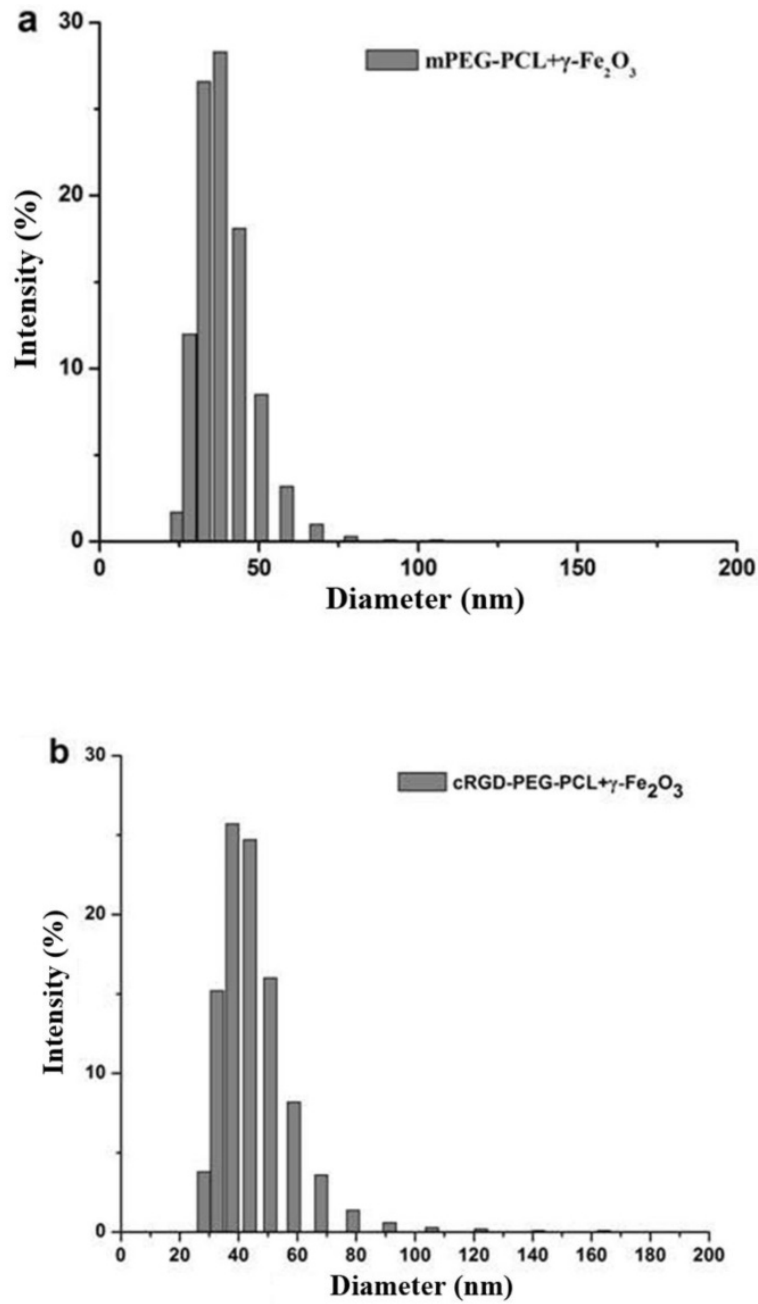

Figure 2. The particle size distribution of non-targeting micelles mPEG-PCL- $\mathrm{y}-\mathrm{Fe}_{2} \mathrm{O}_{3}$ and targeting micelles cRGD-PEG-b-PCL- $\mathrm{y}-$ $\mathrm{Fe}_{2} \mathrm{O}_{3}$. The average particle diameter of non-targeting micelles mPEG-PCL-y- $-\mathrm{Fe}_{2} \mathrm{O}_{3}$ was $38.59 \pm 9.82 \mathrm{~nm}$ (Fig. 2a) and that of targeting micelles cRGD-PEG-b-PCL- $\gamma-\mathrm{Fe}_{2} \mathrm{O}_{3}$ was $44.78 \pm 14.95 \mathrm{~nm}$ (Fig. 2b), both of which are close to $50 \mathrm{~nm}$
Nanoparticles with an irregular sphere were detected (Fig. 3), and some of them encapsulated black $\gamma-\mathrm{Fe}_{2} \mathrm{O}_{3}$ with a uniform particle diameter. The larger the micelle size, the more $\gamma-\mathrm{Fe}_{2} \mathrm{O}_{3}$ nanoparticles it contains. These results suggested that self-assembly of amphiphilic block copolymers and synthesis of polymer micelles loaded with $\gamma-\mathrm{Fe}_{2} \mathrm{O}_{3}$ by ultrasonic emulsification was successful.

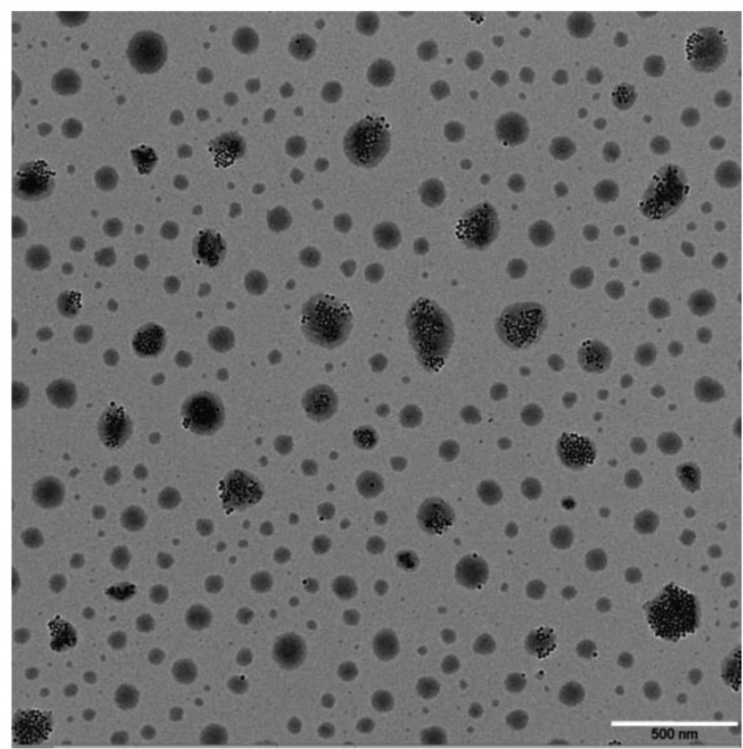

Figure 3. TEM photos of cRGD-PEG-b-PCL-y-Fe $\mathrm{O}_{3}$. Nanoparticles with an irregular sphere were detected, and some of them encapsulated black $\mathrm{Y}-\mathrm{Fe}_{2} \mathrm{O}_{3}$ with a uniform particle diameter. The larger the micelle size, the more $\mathrm{Y}-\mathrm{Fe}_{2} \mathrm{O}_{3}$ nanoparticles it contains.

The $\mathrm{Y}-\mathrm{Fe}_{2} \mathrm{O}_{3}$ nanoparticle loading efficiency under different cRGD concentration of polymer micelles was detected using a UV spectrophotometer (Table 1).

Table 1. The $\mathrm{y}-\mathrm{Fe}_{2} \mathrm{O}_{3}$ nanoparticle loading efficiency under different CRGD concentration of polymer micelles

\begin{tabular}{lll}
\hline $\begin{array}{l}\text { cRGD } \\
\text { molar concentration }\end{array}$ & $\begin{array}{l}\text { loading } \\
\text { efficiency }\end{array}$ & $\begin{array}{l}\text { encaosulation } \\
\text { efficiency } \mathbf{( \% )}\end{array}$ \\
\hline non-targeting group & $0.45 \pm 0.14$ & $3.84 \pm 1.18$ \\
targeting group & $0.44 \pm 0.03$ & $3.90 \pm 0.25$ \\
competitive inhibition group & $1.15 \pm 0.18$ & $10.6 \pm 1.66$ \\
\hline
\end{tabular}

\section{MTT cytotoxicity assay}

The MTT assay showed that the survival rate of ED25 cells was low as the cells were directly cultured with $\gamma-\mathrm{Fe}_{2} \mathrm{O}_{3}$ in very low iron concentrations (2.5 $\mu \mathrm{g} / \mathrm{mL}$ ), demonstrating $\mathrm{\gamma}-\mathrm{Fe}_{2} \mathrm{O}_{3}$ cytotoxicity. In contrast, a high survival rate and proliferation were observed in ED25 cells incubated in $\gamma-\mathrm{Fe}_{2} \mathrm{O}_{3}$-loaded cRGD-PEG-PCL micelles solution for 24 hours, even if the iron concentration was high $(40 \mu \mathrm{g} / \mathrm{mL}$; Fig. 4). These results suggested that $\gamma-\mathrm{Fe}_{2} \mathrm{O}_{3}$-loaded cRGD-PEG-PCL micelles can significantly reduce the cytotoxicity of $\gamma-\mathrm{Fe}_{2} \mathrm{O}_{3}$ nanoparticles. 


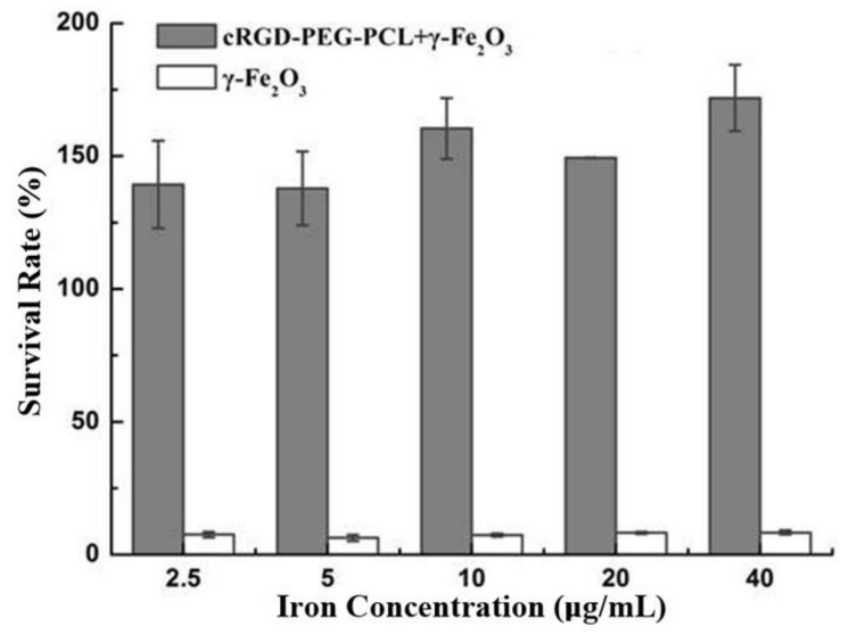

Figure 4. MTT cytotoxicity assay. The MTT assay showed that the survival rate of ED25 cells was low as the cells were directly cultured with $\mathrm{y}-\mathrm{Fe}_{2} \mathrm{O}_{3}$ in very low iron concentrations $(2.5 \mu \mathrm{g} / \mathrm{mL})$. In contrast, a high survival rate and proliferation were observed in ED25 cells incubated in cRGD-PEG-b-PCL- $\gamma-\mathrm{Fe}_{2} \mathrm{O}_{3}$ for 24 hours, even if the iron concentration was high $(40 \mu g / m L)$

\section{Prussian blue staining}

Prussian blue staining experiments revealed a different cell uptake level in targeting, non-targeting and competitive inhibition micelles. Compared to the cells incubated with non-targeting and competitive inhibition micelles, the cells incubated with the targeting micelles showed more blue spots (Fig. 5), indicating better active uptake of targeting micelles by T3A cells.

\section{In vitro MR Imaging}

\section{Polymer micelles MR Imaging}

T2-weighted imaging showed a gradual decrease in signal intensity according to the increase in iron concentration in culture media (Fig. 6). The micelle relaxation rate using T2-mapping showed that the three groups of polymeric micelles have superparamagnetic properties (Table 2).

\section{Cell MR Imaging}

Cell MRI showed that T2WI of the targeting group was significantly lower than that of the non-targeting and competitive inhibition groups (Fig. 7). T2 relaxation time of the targeting group was significantly shorter than that of the other two groups $(P<0.05 ; \mathrm{T} 2$ values of targeting group, non-targeting groups, and competitive inhibition group were $139 \pm 9$ $\mathrm{ms}, 216 \pm 13 \mathrm{~ms}$ and $198 \pm 15 \mathrm{~ms}$, respectively). No significant difference was detected between the non-targeting group and competitive inhibition group $(P>0.05)$. These results indicated that the targeting polymer micelles are actively targeted to the T3A cells and can be easily monitored using clinical $1.5 \mathrm{~T}$ MRI scanner.

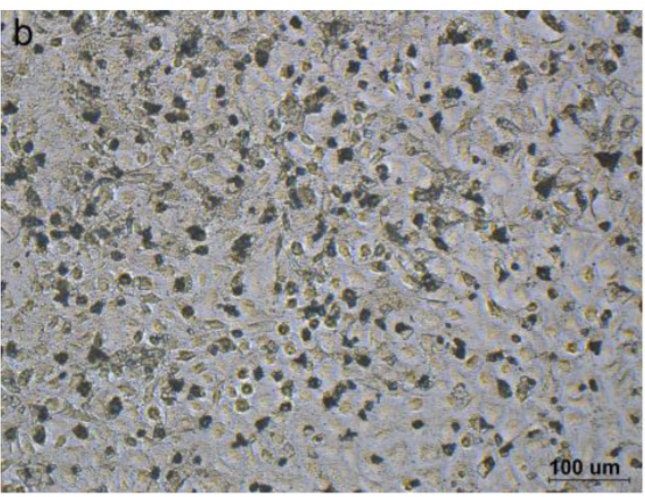

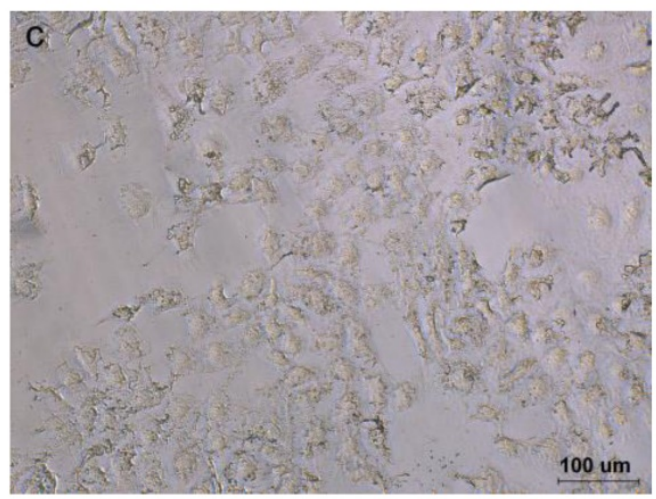

Figure 5. Prussian blue staining. Compared to the cells incubated with non-targeting (Fig. 5a) and competitive inhibition micelles (Fig. 5c), the cells incubated with the targeting micelles (Fig. $5 \mathrm{~b}$ ) showed more blue spots, indicating better active uptake of targeting micelles by T3A cells. 


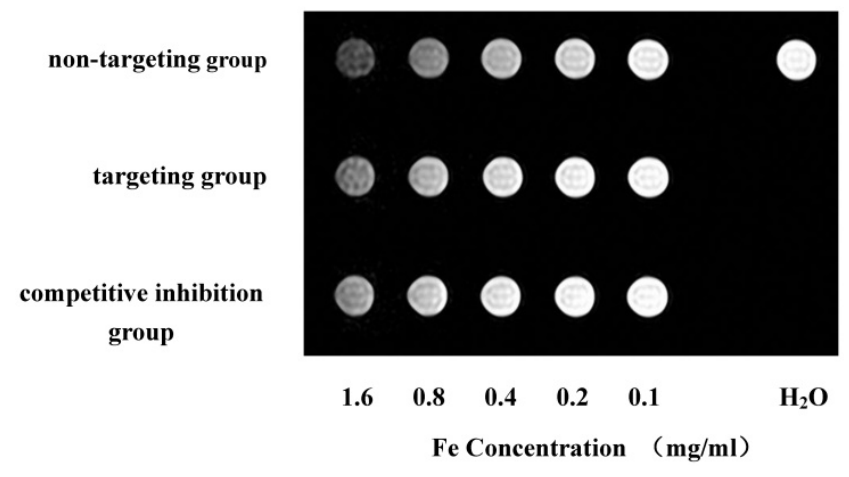

Figure 6. Polymer micelles MR Imaging. T2-weighted imaging showed a gradual decrease in signal intensity according to the increase in iron concentration in culture media.

Table 2. The micelle relaxation rate using T2-mapping ( $\left.\mathrm{mM}^{-1} \mathrm{~S}^{-1}\right)$

\begin{tabular}{llll}
\hline & $\begin{array}{l}\text { non-targeting } \\
\text { group }\end{array}$ & $\begin{array}{l}\text { targeting } \\
\text { group }\end{array}$ & $\begin{array}{l}\text { competitive } \\
\text { inhibition group }\end{array}$ \\
\hline $\mathbf{R}_{\mathbf{2}}$ & 0.3705 & 0.1872 & 0.1139 \\
$\mathbf{R}_{\mathbf{1}}$ & 0.0019 & 0.0015 & 0.0011 \\
$\mathbf{R}_{\mathbf{2}} / \mathbf{R}_{\mathbf{1}}$ & 195.00 & 124.80 & 103.55 \\
\hline
\end{tabular}

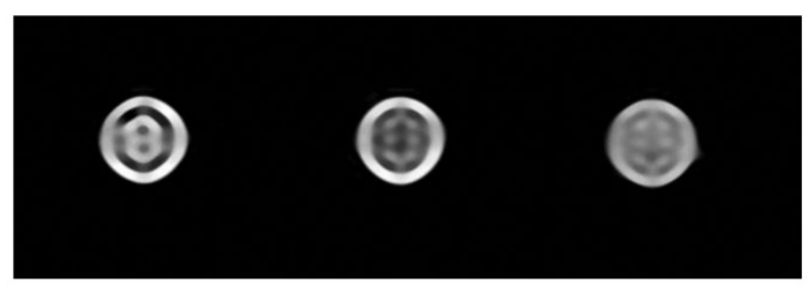

A

B

C

Figure 7. Cell MR Imaging. Cell MR Imaging showed that T2WI of the targeting group (Figure $7 \mathrm{~b}$ ) was significantly lower than that of the non-targeting (Figure 7a) and competitive inhibition groups (Figure 7c).

\section{Discussion}

MRI is a useful diagnostic technique which can provide noninvasive and real time disease detection. Application of effective contrast agents has been regarded as a feasible means to improve lesion detection rates and qualitative diagnostic capabilities. However, current clinically-used contrast agents, such as Gd-DTPA and SPION, have a relatively low MRI sensitivity, a short half-life, and non-specific distribution. It is difficult to modify them with biological macromolecules and they are unsuitable as targeting ligands for molecular-targeting imaging [12, 13, 18]. Design and synthesis of high affinity MRI molecular probes targeting tumor specific molecules, resulting in extension of the half-life and an increase in sensitivity and targeting, is a highly desirable strategy to improve low MRI sensitivities, early tumor diagnosis, and micro-lesion detection.

In order to achieve tumor-specific targeted imaging, it is necessary to use a contrast agent with a smaller particle size and specific organization distribution, which can be achieved using nano-technology. Nanoparticles have the following unique advantages [11-13, 19, 20]: 1) Nanoparticles have unique nano-size $(10-100 \mathrm{~nm})$, which helps to reduce renal clearance, reticuloendothelial system (RES) absorption, and phagocyte recognition, which extends the circulation time and half-life. 2) Nanoparticles reach the tumor tissue through capillary endothelial cell gaps and passive targeting, and accumulate in tumors via an enhanced permeability and retention (EPR) effect. 3) Nanoparticles loaded with specific ligands that can recognize the molecules on tumor cell membranes to achieve active targeting. 4) Targeted nanoparticle transport can reduce cytotoxicity. The multifunctional polymeric micelles, which are synthesized using amphiphilic biblock copolymer and self-assembly, possess a unique core-shell structure. The hydrophilic shell makes micelles highly dispersible in a water-soluble internal environment and transferable to a specific location via the blood circulation, while the hydrophobic core can accommodate hydrophobic drugs or a controllable nano-drug release library using imaging contrast agents [11-13, 19, 20]. In addition, the micelle diameter can be maintained in the range of 10-100 $\mathrm{nm}$ by controlling the polymer structure, MRI contrast agents and hydrophobic drugs that are encapsulated into the micelle core by hydrophobic interactions.

In this study, we used the polymeric micelles, PEG-PCL, as the carrier, connected its shell with the targeting ligand cRGD of the integrin av $\beta 3$ receptor to obtain an active targeting effect, and loaded superparamagnetic $\gamma-\mathrm{Fe}_{2} \mathrm{O}_{3}$ into the micelle core to provide supermagnetic sensitivity. In this manner, we synthesized the multifunctional $\gamma-\mathrm{Fe}_{2} \mathrm{O}_{3}$-loaded cRGD-PEG-PCL micelles that are actively targeted to carcinoma vascular endothelial cells, and that have a small size and supermagnetic sensitivity. The block polymer characteristics were analyzed using a transmission electron microscope, ${ }^{1} \mathrm{H}$ NMR spectra and mass spectrometry, which showed that the cRGD targeting ligand was successfully connected to the shell of PEG-PCL and $\gamma-\mathrm{Fe}_{2} \mathrm{O}_{3}$ nanoparticles were efficiently loaded into the core of block polymers. The synthesized polymeric micelles had a small size (about $50 \mathrm{~nm}$ ) and supermagnetic sensitivity, and the $\mathrm{R} 2$ and $\mathrm{R} 2 / \mathrm{R} 1$ were higher than the usual $\mathrm{T} 2$ negative contrast agents (such as Feridex) [21].

$\mathrm{Fe}_{3} \mathrm{O}_{4}$ and $\gamma-\mathrm{Fe}_{2} \mathrm{O}_{3}$ are superparamagnetic iron oxides, and we used $\gamma-\mathrm{Fe}_{2} \mathrm{O}_{3}$ in our study. In this study, we prepared $\gamma-\mathrm{Fe}_{2} \mathrm{O}_{3}$-loaded cRGD-PEG-PCL micelles with various CRGD concentrations using the same molar ratio of hydrophilic-to-hydrophobic as in 
PEG-PCL to ensure the same length and number of hydrophobic PCL in each sample group. The polymeric micelle load capacity for $\gamma-\mathrm{Fe}_{2} \mathrm{O}_{3}$ was cRGD concentration-dependent, with the $\mathrm{\gamma}^{-} \mathrm{Fe}_{2} \mathrm{O}_{3}$ load increasing along with increase in the cRGD concentration. The $\gamma-\mathrm{Fe}_{2} \mathrm{O}_{3}$ encapsulation efficiency reached $10.6 \%$ when the cRGD concentration was $100 \%$, which was about 2.7-fold higher than the non-targeting group, which had $0 \%$ cRGD concentration, indicating a better amphiphilic block polymer load capacity for $\gamma-\mathrm{Fe}_{2} \mathrm{O}_{3}$ and linking with cRGD. The load of cRGD did not significantly increase the overall size of micelle. Moreover, the relative increased average particle size means an increase in micelles with large particles and a larger hydrophobic core can accommodate more $\gamma-\mathrm{Fe}_{2} \mathrm{O}_{3}$, resulting in an improvement of load and encapsulation efficiency. Since the surface area of the micelles increases by molecular exclusion of cRGD on the micelle surface, the micelle core becomes consistently looser, which contributed to a higher encapsulation efficiency with hydrophobic $\gamma-\mathrm{Fe}_{2} \mathrm{O}_{3}$.

Prussian blue staining confirmed that the targeted micelles have better active targeting to in human hepatic vascular endothelial cells, resulting in more blue-stained iron particles in the T3A cells. Lack of active targeting to T3A cells in the non-targeting micelles, which did not have the targeting ligand cRGD connection, led to sparse blue-stained iron particles in the T3A cells. The integrin av $\beta 3$ receptor binding sites on the cell surface reached saturation due to the high level of cRGD in the competitive inhibition group, which inhibited uptake of micelles into T3A cells.

In vitro $M R$ imaging further confirmed that targeting micelles have an active targeting effect on human hepatic carcinoma vascular endothelial cells and can be monitored using clinical MRI. The tumor vascular endothelial cells can actively take up more micelles containing $\gamma-\mathrm{Fe}_{2} \mathrm{O}_{3}$, which was a result of specific binding to the targeting ligand, cRGD with tumor integrin av $\beta 3$ receptors, in the targeting group. A significantly lower T2WI signal was detected in the targeting group, rather than the slightly lower signals in the non-targeting and competitive inhibition groups. T2 relaxation time in the targeting group was significantly shorter than in the other two groups.

The MTT results showed that the $\gamma-\mathrm{Fe}_{2} \mathrm{O}_{3}$-loaded cRGD-PEG-PCL micelle can significantly reduce $\gamma-\mathrm{Fe}_{2} \mathrm{O}_{3}$ cytotoxicity. The cells had a high survival rate and even proliferated in the presence of high iron concentrations $(40 \mu \mathrm{g} / \mathrm{mL})$, supporting the biological safety of synthesized polymer micelles.

\section{Conclusion}

In summary, we successfully synthesized multifunctional polymer micelles with active targeting to carcinoma vascular endothelial cells. These micelles had a small particle size and supermagnetic sensitivity, and they were used as a drug-delivery system for imaging contrast compounds and anti-angiogenics. These results indicated that the $\gamma$ - $\mathrm{Fe}_{2} \mathrm{O}_{3}$-loaded cRGD-PEG-PCL micelle have better active targeting and low cytotoxicity on human hepatic carcinoma vascular endothelial cells, which can be monitored using clinical 1.5 T MRI scanner.

\section{Acknowledgements}

This research was supported by the National Natural Science Foundation of China (81271561, 30900357), the Natural Science Foundation of Guangdong Province (2015A030313173).

\section{Competing Interests}

The authors have declared that no competing interest exists.

\section{References}

1. http://www.who.int/mediacentre/factsheets/fs297/zh/

2. Folkman J. Role of angiogenesis in tumor growth and metastasis. Semin Oncol 2002;29:15-18. [PMID: 12516034]

3. Risau W. Mechanisms of angiogenesis. Nature 1997;386:671-674. [PMID:9109485]

4. Jain RK. Molecular regulation of vessel maturation. Nat Med 2003;9:685-693. [PMID:12778167]

5. Winter PM, Caruthers SD, Kassner A,Harris TD,Chinen LK,Allen JS,Lacy EK,Zhang H,Robertson JD,Wickline SA,Lanza GM. Molecular imaging of angiogenesis in nascent $\mathrm{Vx}-2$ rabbit tumors using a novel av 33 -targeted nanoparticle and 1.5 tesla magnetic resonance imaging. Cancer Research 2003;63:5838-5843. [PMID:14522907]

6. Kubota Y. Tumor angiogenesis and anti-angiogenic therapy. Keio J Med 2012; 61(2):47-56. [PMID:22760023]

7. Wenjuan Li, Yong Wang, Yulin Liu, Teng Wu, Wenli Cai, Xintao Shuai, Guobin Hong. Preliminary Study of MR and Fluorescence Dual-mode Imaging: Combined Macrophage-Targeted and Superparamagnetic Polymeric Micelles. International Journal of Medical Sciences 2018; 15(2): 129-141.

8. Kukowska-Latallo JF, Candido KA, Cao Z, Nigavekar SS,Majoros IJ,Thomas TP,Balogh LP,Khan MK,Baker JR. Nanoparticle targeting of anticancer drug improves therapeutic response in animal model of human epithelial cancer. Caner Res 2005;65(12):5317-5324. [PMID:15958579]

9. Konda SD, Aref M, Wang S, Brechbiel M,Wiener EC. Specific targeting of folate-dendrimer MRI contrast agents to the high affinity folate receptor expressed in ovarian tumor xenografts. MAGMA 2001;12(2):104-113. [PMID:11390265]

10. Lu Y, Low PS. Immunotherapy of folate receptor-expressing tumors: review of recent advances and future prospects (Review). J Control Release 2003;91(1): 17-29. [PMID:12932634]

11. Choi H, Choi SR, Zhou R, Kung KF, Chen IW. Iron oxide nanoparticles as magnetic resonance contrast agent for tumor imaging via folate receptor-targeted delivery. Acad Radio 2004;11(9):996-1004. [PMID:15350580]

12. Guobin Hong, Renxu Yuan, Biling Liang, Jun S, Xiaoqiang Yang, Xintao Shuai. Folate-functionalized polymeric micelle as hepatic carcinoma-targeted, MRI-ultrasensitive delivery system of antitumor drugs. Biomed Microdevices 2008;10(5):693-700. [PMID:18350380]

13. Yang XQ, Deng WJ, Fu LW, Blanco E, Gao JM,Quan DP, Shuai XT. Folate-functionalized polymeric micelles for tumor targeted delivery of a potent multidrug-resistance modulator FG020326, J Biomed Mater Res A 2008;86(1):48-60. [PMID:17941015]

14. Du Cheng, Guobin Hong, Weiwei Wang, Renxu Yuan,Hua Ai,Jun Shen,Biling Liang,Jinming Gao,Xintao Shuai. Nonclustered magnetite nanoparticle encapsulated biodegradable polymeric micelles with enhanced properties for in vivo tumor imaging. J Mater Chem 2011;21(13):4796-4804. [DOI:10.1039/c0jm03783d] 
15. Wang W, Cheng D, Gong FM,Miao XS,Shuai XT. Design of multifunctional micelle for tumor-targeted intracellular drug release and fluorescent imaging. Adv Material 2012;24(1): 115-120. [PMID:22143956]

16. Guo Q, Teng X, Rahman S, Yang H. Patterned Langmuir-Blodgett Films of Monodisperse Nanoparticles of Iron Oxide Using Soft Lithography. J Am Chem Soc 2002;125(3): 630-631. [PMID:12526652]

17. Kiwada, H, Sato J, Yamada S, Kato Y. Feasibility of Magnetic Liposomes as a Targeting Device for Drugs. Chem Pharmaceut Bull 1986;34(10): 4253-4258. [PMID:3829157]

18. Yu S, Chow GM. Carboxyl group (-CO2H) functionalized ferrimagnetic iron oxide nanoparticles for potential bio-applications. J Mater Chem 2004; 14:2781-2786. [DOI: 10.1039/B404964K]

19. Sun SH, Zeng H, Robinson DB, Raoux S,Rice PM,Wang SX,Li G. Monodisperse MFe2O4 ( $\mathrm{M}=\mathrm{Fe}, \mathrm{Co}, \mathrm{Mn})$ Nanoparticles. J Am Chem Soc 2004;126:273-279. [PMID:14709092]

20. Maier CF, Tan SG, Hariharan H, Potter HG. T2 quantitation of articular cartilage at 1.5T. JMRI 2003;17:358-364. [PMID:12594727]

21. Wang YX, Hussain SM, Krestin GP. Superparamagnetic iron oxide contrast agents: physicochemical characteristics and applications in MR imaging. Eur Radiol 2001;11(11):2319-2331. [PMID:11702180] 